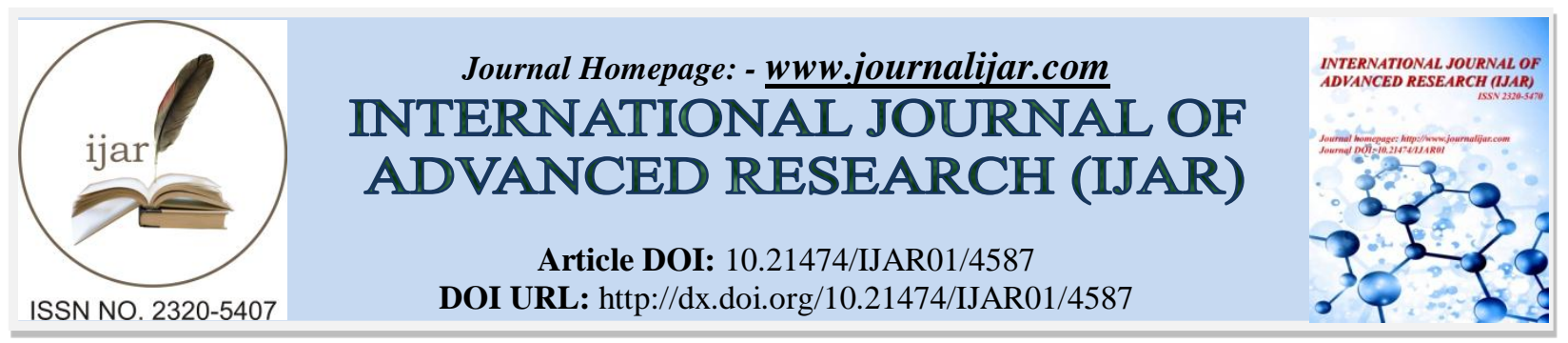

RESEARCH ARTICLE

\title{
PREVALENCE OF WORK-RELATED MUSCULOSKELETAL DISORDERS AMONG HOUSING CONSTRUCTION WORKERS IN MOMBASA COUNTY, KENYA.
}

Peninnah Muthoki Kisilu ${ }^{1}$, Prof. Erastus Gatebe ${ }^{1}$ and Dr. Joseph B. Msanzu ${ }^{2}$.

1. Department of Occupational Safety and Health, Institute of Energy and Environmental Technology, Jomo

Kenyatta University of Agriculture and Technology, Kenya.

2. Department of Pure and Applied Sciences, Technical University of Mombasa, Kenya.

\section{Manuscript Info}

Manuscript History

Received: 24 April 2017

Final Accepted: 26 May 2017

Published: June 2017

Key words:-

Ergonomics: The science of designing the job to fit the worker, not forcing the worker to fit the job.

Ergonomic risk factors: Aspects of a job that pose a biomechanical stress to the worker e.g. Force, Repetition, Awkward postures, Static postures, Contact stress and Vibration

MSD symptoms: Physical indications that an employee may be developing an MSD.

Musculoskeletal Disorders (MSDs): Conditions where parts of the musculoskeletal system are injured resulting from the buildup of trauma and are ascertained on the basis of frequent pain and a duration with symptoms persisting for at least three days.

Occupier: Means the person or persons in actual occupation of a workplace, whether as the owner or not and includes an employer.

Prevalence: A dimensionless unit that gives the frequency of a disorder or the proportion of a population that experiences it, at a specified point in time.

\section{Abstract}

Work-related musculoskeletal disorders (MSDs) are a major cause of functional impairment and disability among housing construction workers worldwide. A good understanding of ergonomic risk factors in the housing construction industry and the prevalence of MSD symptoms is paramount in implementing the right preventive measures among the construction workers. The main objective of this study was to determine the prevalence of work related MSDs among housing construction workers in Mombasa County, Kenya. Specifically, the study endeavored to find out the occupational activities that can lead to a worker developing MSD symptoms, the presence of MSD symptoms among housing construction workers, the association of MSD symptoms with work activities and the preventive measures put in place to control MSD symptoms among housing construction workers in the selected County. Descriptive cross sectional study design was used. Stratified random sampling was applied to draw a random sample of 354 housing construction workers. Self-administered questionnaires were used for both casual and permanent housing construction workers so as to identify the relationship between duties performed by a worker and the severity of MSD symptoms. An observation checklist was used to record how activities were performed by workers. Data collected from the questionnaires was cleaned, coded, tabulated and subjected to statistical analysis for calculation of frequencies and means. Statistical Package for Social Sciences (SPSS) Version 20.00 was used to analyze the quantitative data while content analysis was used to analyze qualitative data. Multiple regression analysis was carried out to test and determine the prevalence of MSD symptoms among housing construction workers in relation to occupational activities performed, presence of MSD symptoms and extent to which the MSD symptoms were perceived by the respondents as work-related. It was established that majority of housing construction workers in Mombasa County experience regular body pain $(98.1 \%)$ and that the body pain was caused by the nature of their work. Among those affected, $12 \%$ reported pain of the neck, shoulders and hands while $86.1 \%$ reported pain of upper and lower limb, knees, ankles and feet. The study also 
established that factors contributing most to MSDs were physical factors (61\%), work procedures (27.3\%), and exposure history $(11.7 \%)$. The regression analysis established that taking occupational activities, presence of MSD symptoms and perception of MSDs to work-relatedness factors constant at zero, the prevalence of MSDs would be $0.689(68.9 \%)$. A unit increase in occupational activities, presence of MSDs symptoms and extent to which MSDs are perceived as work-related factors, lead to a $0.716(71.6 \%)$ increase in prevalence of MSDs. Further, it was observed that at $5 \%$ level of significance ( $95 \%$ level of confidence), workplace activities and work procedures, had a 0.000 level of significance. The Chi square was calculated and the value obtained was 0.657, ( $\mathrm{p}$-value 0.000).This shows that the variable was significant $(\mathrm{p}<0.05)$ and the data obtained is significant. The body mass index data also showed $2 \%$ correlation between exposure to MSDs and BMI. This is the first research to demonstrate influence of BMI and MSDs exposure in Mombasa County.

Copy Right, IJAR, 2017,. All rights reserved.

\section{Introduction:-}

Work-related musculoskeletal disorders (MSDs) are a major cause of functional impairments and disability among housing construction workers worldwide due to the strenuousness of the construction activities (Bernard, 2010). Compared to non-construction occupations, construction occupations require greater amounts of strength and involve more stooping, crawling, crouching kneeling, climbing and balancing (Schnieder, 2001). Additionally, construction workers are exposed to high physical demands such as heavy lifting; repetitive motions and awkward working postures (Centre for Construction Research and Training, 2013). Construction workers face higher rates of MSDs (approximately 16\% higher) than workers in other industries (Stattin et al., 2005).

Musculoskeletal disorders among housing construction workers is a major challenge not only to developing nations like Kenya but also to the developed countries. The Swedish construction work environment, for instance, is regarded as the safest in the world as far as working conditions and musculoskeletal health is concerned (Flanagan et al., 2001). However, MSDs form the biggest percentage of most compensated illnesses among all workers in Sweden (Swedish Social Insurance Agency, 2004). Additionally, according to the U.S National Research Council and the Institute of Medicine (2001), musculoskeletal disorders account for nearly 70 million physician office visits in the United States annually, and an estimated 130 million total health care encounters including outpatient, hospital, and emergency room visits.

The Kenyan housing construction industry is rapidly growing as a result of increased population and this has come with safety and health implications. According to Kenya DOSHS records, 7,769 fatalities were reported across all sectors in Kenya between 2005 and 2009 and in the year 2011 alone, the construction industry accounted for $16 \%$ of all fatal accidents (DOHS Annual Report 2011). Although MSDs form a major part of construction injuries in Kenya, there is no properly documented data on MSDs in the housing construction industry but recent studies and the enactment of the National Construction Authority Act 2011, are addressing this challenge. This made it necessary to carry out research on the prevalence of MSDs among housing construction workers in Mombasa County which has one of the highest construction activities in the country due to its increasing population and rapid urbanization. The National Construction Authority regulations of 2014 require all contractors to be assessed in terms of skills and only the competent ones issued with a certificate to participate in construction activities. This is in attempt to control quack constructors who risk the lives of employees and occupants of substandard buildings which has seen a steep rise of construction accidents in the recent past in Kenya (NCA, 2016). Additionally, OSHA, 2007 states that every employer shall take necessary steps to ensure that workstations, equipment and work tasks are adapted to fit the employee and the employee's ability so as to avoid MSDs. This research set out to evaluate the implementation of these provisions in Mombasa County. 


\section{Methodology:-}

Research Design:-

Descriptive cross-sectional design was used in this study which is a research design that investigates exposure to risk factors and outcomes as well as estimating the prevalence of the outcome within relatively short time in a population with respect to an outcome and set of risk factors (Levin Kate, 2006).

\section{Population:-}

The target population was 4,400 housing construction workers, drawn from construction sites that were registered with the National Construction Authority by the time of data collection and had ongoing housing construction projects and distributed within the four sub-counties as shown in Table 1.

Table 1:- Population distribution

\begin{tabular}{|c|c|c|}
\hline Sub-County & Number of registered housing projects & Total number of workers \\
\hline Mvita & 15 & 2,117 \\
\hline Kisauni & 23 & 2,165 \\
\hline Changamwe & 5 & 98 \\
\hline Likoni & 1 & 20 \\
\hline Total & 44 & 4,400 \\
\hline
\end{tabular}

\section{Sampling Frame:-}

Stratified random sampling was used to divide the population into 12 strata based on the specific work performed or job cadre namely; engineers, site contractors, foremen, masons, plasterers, carpenters, roofers, plumbers, painters, electricians, steel fixers and unskilled casual workers(Table2).

Table 2:- Sample distribution per job cadre

\begin{tabular}{|c|c|c|}
\hline Cadre/group & Target population & Sample \\
\hline Engineers & 44 & 4 \\
\hline Supervisors/foremen & 44 & 4 \\
\hline Site contractors & 44 & 4 \\
\hline Masons & 660 & 53 \\
\hline Plasters & 660 & 53 \\
\hline Carpenters & 176 & 14 \\
\hline Roofers & 176 & 14 \\
\hline Plumbers & 88 & 7 \\
\hline Painters & 132 & 11 \\
\hline Electricians & 88 & 7 \\
\hline Steel fixers & 88 & 7 \\
\hline Unskilled casual workers & 2,200 & 176 \\
\hline Total & $\mathbf{4 , 4 0 0}$ & $\mathbf{3 5 4}$ \\
\hline
\end{tabular}

\section{Sample size Determination:-}

Simple random sampling was used in this study to obtain a representative sample. The 4,400 housing construction workers were divided into 12 strata and a random sample picked from each stratum. Since the target population in this study was finite, Krejcie (1970) formula was used to get the sample size;

Where,

$$
\mathrm{n}=\left(\mathrm{X}^{2} \mathrm{Npq}\right) /\left(\mathrm{d}^{2}(\mathrm{~N}-1)+\mathrm{X}^{2} \mathrm{pq}\right)
$$

$\mathrm{n}=$ desired sample size; $\mathrm{N}=$ Target population

$\mathrm{p}=$ population proportion $(0.5$ at $95 \%$ confidence level $)$

$\mathrm{q}=1-\mathrm{p}$

$\mathrm{d}=$ degree of accuracy reflected by the amount of error that can be tolerated at $95 \%$ confidence level.

$\mathrm{X}^{2}=$ the chi square table value for one degree of freedom relative to the desired level of confidence $\left(\mathrm{X}^{2}=3.841\right.$ at $95 \%$ confidence level).

Hence, $\mathrm{n}=\left(\mathrm{X}^{2} \mathrm{Npq}\right) /\left(\mathrm{d}^{2}(\mathrm{~N}-1)+\mathrm{X}^{2} \mathrm{pq}\right)$ 
$\mathrm{n}=3.841 * 4400 * 0.5 * 0.5 /\left(0.05^{2}(4400-1)+3.841 * 0.5 * 0.5\right)$

$\mathrm{n}=354$.

\section{Data Analysis:-}

Primary data was collected through self-administered semi-structured questionnaires and an observation checklist. The questionnaire addressed occupational activities that can cause MSDs, the presence of MSDs among the workers, the perception of MSDs to be work-related and the preventive measures put in place to control MSDs. The observation checklist was used to record how work activities were being carried out, the weights being lifted, the postures applied while working and the duration it took to perform a task. Secondary data was collected through review of existing records on MSDs in the housing construction sector from DOSHS and hospital health records. A pilot study was carried out in Kwale, a neighboring County to the selected County. In the pilot study, the questionnaire was given to just a few people with an intention of pre-testing the questions to assist in determining if there were flaws, limitations or other weaknesses hence necessary revisions prior to the implementation of the study as stated by Babbie,(2004). Cronbach alpha was used to test the validity and reliability of the data collection instruments. The reliability of the research instrument on work activities was found to be $(\alpha=0.806)$, frequently incurred MSDS $(\alpha=0.771)$ while perception of MSDS to work relatedness had a value $(\alpha=0.728)$ all of which were above the acceptable level of 0.70 (Hair et al., 1998). Quantitative data gathered from questionnaires was cleaned, coded, tabulated and entered into Statistical Package for Social Sciences (SPSS) Version 20.0 for analysis. Descriptive statistics was used to summarize the responses. For qualitative data, content analysis was applied to examine the intensity with which certain themes were used and systematically describe the content of written or spoken material. This helped to capture the in-depth opinions of the respondents. Multiple regression analysis was conducted to test and determine the prevalence of musculoskeletal disorders among housing construction workers in relation to occupational activities, presence of MSDs and workers' perception of MSDs to be work-related.

\section{Results and Discussion:-}

The presented findings had a response rate of 74.6\%. According to Mugenda and Mugenda (1999), a response rate of $50 \%$ is adequate for analysis and reporting, a rate of $60 \%$ is good and a response rate of $70 \%$ and over is excellent. The respondents were randomly picked from the targeted job cadre namely: supervisors, engineers, contractors, masons, plasterers, carpenters, roofers, plumbers, painters, electricians, steel fixers and the unskilled casual workers. Demographic characteristic was captured in order to understand the causes of MSDs within workers in the housing construction industry. Table 3 depicts the gender, age, education level and the number of years worked by the respondents in the construction industry.

Table 3:- Socio-demographic information of the respondents

\begin{tabular}{|c|c|c|c|}
\hline Variable & Trait & Frequency & Percent (\%) \\
\hline Gender & Male & 262 & 99.2 \\
\hline Age (years) & Female & 2 & 0.8 \\
\hline & $0-18$ & 0 & 0 \\
\hline & $19-29$ & 94 & 35.6 \\
\hline & $30-39$ & 108 & 40.9 \\
\hline & $40-49$ & 47 & 17.8 \\
\hline & $50-59$ & 13 & 4.9 \\
\hline & 60 and above & 2 & 0.8 \\
\hline Education level & Never attended school & 26 & 9.8 \\
\hline & Primary & 73 & 27.7 \\
\hline & Secondary & 84 & 31.8 \\
\hline Years worked & Tertiary/college/University & 81 & 30.7 \\
\hline & $3-8$ & 135 & 51.1 \\
\hline & $9-14$ & 76 & 28.8 \\
\hline & $15-20$ & 40 & 15.2 \\
\hline
\end{tabular}

The weight of the respondents was also taken using equinox analogue weighing scale which is easy to use and gives high accuracy while their height was taken using a plastic tape measure and the Body Mass Index (BMI) calculated. This was aimed at establishing the health status of the workers as the BMI would be able to determine the 
probability of these workers falling or being prone to MSDs due to repetitive work accompanied by high force requirement. The BMI was categorized into four classes namely; underweight (BMI less than 18.5), Normal weight (BMI between 18.5 to 24.9), overweight (BMI of 25 to 29.9) and obese (BMI over 30) according to classification of BMI by (www.wbmd.com/guides/body mass-index for adults). In this study, most respondents (98.5\%) had a normal BMI. However, carrying heavy weights repetitively was found to cause MSDs among these workers. The overweight respondents were from the permanent job cadre (contractors, engineers) as shown in Table 4.

Table 4:- Body Mass Index (BMI) of respondents

\begin{tabular}{|c|c|c|c|c|c|}
\hline Average Weight (Kg) & Average height (feet) & Frequency & Percent (\%) & BMI & Remarks \\
\hline 49.5 & 4.8 & 28 & 10.6 & 24.5 & Normal \\
\hline 59.5 & 5.3 & 137 & 51.9 & 23.2 & Normal \\
\hline 69.5 & 5.8 & 90 & 34.1 & 23.2 & Normal \\
\hline 80.0 & 6.1 & 5 & 1.9 & 23.4 & Normal \\
\hline 87.5 & 5.8 & 4 & 1.5 & 29.2 & Overweight \\
\hline
\end{tabular}

Relationship of exposure history and MSDs Symptoms:-

This study found out that exposure history contributes to a worker developing MSDs. Some respondents, 11.7\% indicated that the number of years they had worked in the housing construction industry contributed to development of MSDs symptoms. More men than females $(99.2 \%)$ were exposed to ergonomic risk factors in the housing construction industry in Mombasa County according to the findings of this study as the industry is male dominated. Also, those exposed most are the youth as it was established that majority of the respondents (76.5\%) were in the age bracket of 19-49 years while a few (5.7\%) were above 50 years of age (Fig. 1). This can be attributed to the fact that the youth are more energetic compared to their older counter parts. Bernard (2010) affirms that construction work is very strenuous and physically demanding. Housing construction workers also retire early as it was established that most of the respondents (95.1\%) had worked in the housing construction sector for 3-20 years while only $4.9 \%$ had worked for over 20 years. This study finding agrees with Ekberg et al., (1995) who found a strong relationship between age and development of MSDs among Swedish workers as they tend to go on early retirement as a result of MSDs.

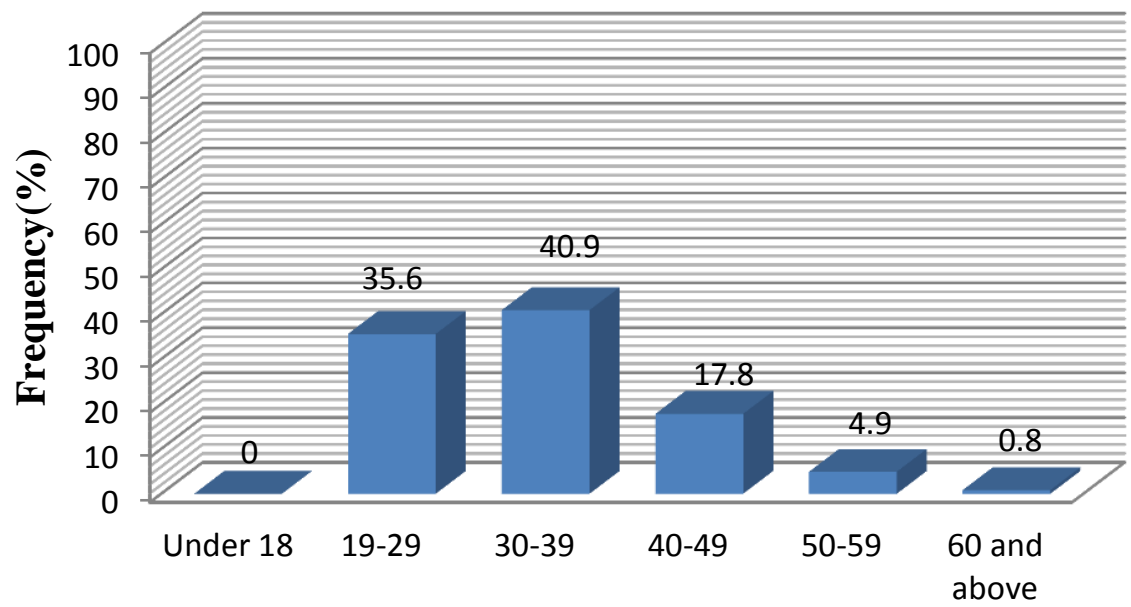

Age

Figure 1:- Age distribution of respondents

Relationship of work procedures and MSD Symptoms:-

From the current study, 27.3\% of the respondents indicated that workplace procedures (organizational factors) contributed to MSDs symptoms. Work procedures here referred to the condition of tools and equipment used while working, the number of working hours, job rotation, and provision of personal protective equipment and allocated workload. 
The study has also found that majority of the respondents $(64.4 \%$,) indicated that the tools and equipment they used for work were never serviced, while only $12.9 \%$ indicated that their tools were always serviced. This implies that most of the tools and equipment used in housing construction industry in Mombasa County are basically not serviced and as a result worker's safety is at risk. This is in contradiction to the Occupational Safety and Health Act (OSHA 2007) which states that machinery, equipment, personal protective equipment, appliances and hand tools used in all workplaces shall comply with the prescribed safety and health standards and be appropriately installed, maintained and safe guarded (OSHA, 2007). Additionally, an employer is liable to pay compensation in accordance with the provisions of Work Injury Benefits Act (WIBA, 2007) to an employee injured while at work if it is deemed as a result of negligence.

On use of improvised tools, $17 \%$ of the respondents had used improvised tools at times in order to complete the assigned workload. According to Kenya OSHA (2007), all tools and equipment should be properly maintained and serviced. Improvised tools pose a risk to the user as one is required to apply more force to perform a task, perform the task repetitively and take long time to complete thus exposing the worker to MSDs and risk of injuries (Plate 1).

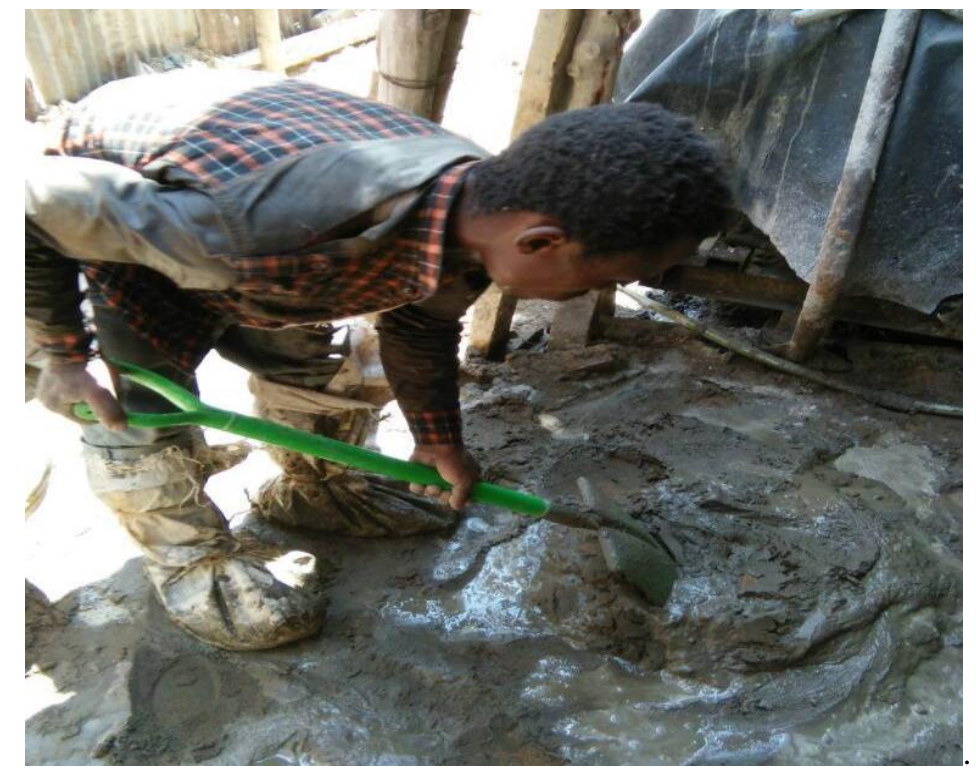

Plate 1:- A worker mixing concrete in bending posture with improvised shoes and no PPE

This study also found that $27.3 \%$ of the respondents were working for more hours (9-16 hours) in contradiction to the Kenyan laws that require employees to work for 8 hours in a day (Labour Institution Act,2007). The reason for working for more hours was to complete the assigned workload for the day which was unreasonably high. Allocation of huge workload to employees contravenes the requirements of OSHA, 2007, which states that every employer shall take necessary steps to ensure that workstations, equipment and work tasks are adapted to fit the employee and the employee's ability including protection against mental strain.

It was also established that majority (95.5\%) of the respondents did not have job rotation so the whole working hours were spend doing the same task. OSHA, 2007 requires that employees be given breaks in between working hours to rest. Working for long hours without breaks and job rotation contributes to a worker developing musculoskeletal disorders (DHHS) (NIOSH, 1997).

Similarly, a significant number of respondents $(95.5 \%)$ did not have or make use of PPE while at work. According to Kenya OSHA, 2007, the law states that every employer shall provide and maintain for the use of employees in any workplace where employees are employed in any process involving exposure to wet or to any injurious or offensive substance, adequate, effective and suitable protective clothing and appliances, including, where necessary, suitable gloves, footwear, goggles and head coverings. The same Act also states that an employee shall at all times wear or use any protective equipment or clothing provided by the employer for the purpose of preventing risks to his safety and health. An employee who contravenes the provisions of this Act commits an offence and shall, on 
conviction, be liable to a fine not exceeding fifty thousand shillings or to imprisonment for a term not exceeding three months or to both (OSHA, 2007).

\section{Observed work activities which leads to MSDs:-}

Most of the respondents (61\%) reported that physical factors (occupational activities) contributed to development of MSDs symptoms. Ergonomics advocates for designing the workplace/job to fit the worker and not the worker to fit the job (OSHA, 2007). It was observed during this study that most occupational activities for housing construction workers involved lifting/moving heavy weights, doing repetitive jobs, working in awkward postures, working with arms above shoulder level and standing for long hours which lead to a worker developing MSDs.

It was also observed that casual workers ferried coral building blocks on their shoulders to the areas they were required especially to upper floors. For instance; a worker could carry about 500 blocks from ground to first or second floors in a building in a day and the average weight of a standard grade two building block which is commonly used in Mombasa County was 10 kilograms. When moving them to third or upper floors, the average blocks carried per person per day was 200 blocks (Plate 2). This heavy weight with a lot of repetition and climbing movement causes MSDs. This finding agrees with Hoogendoorn et al., (1999) who asserts that heavy physical work, for example lifting and carrying, pushing, pulling and manipulating heavy load as in the construction industry is a classic task leading to the development of MSDs.

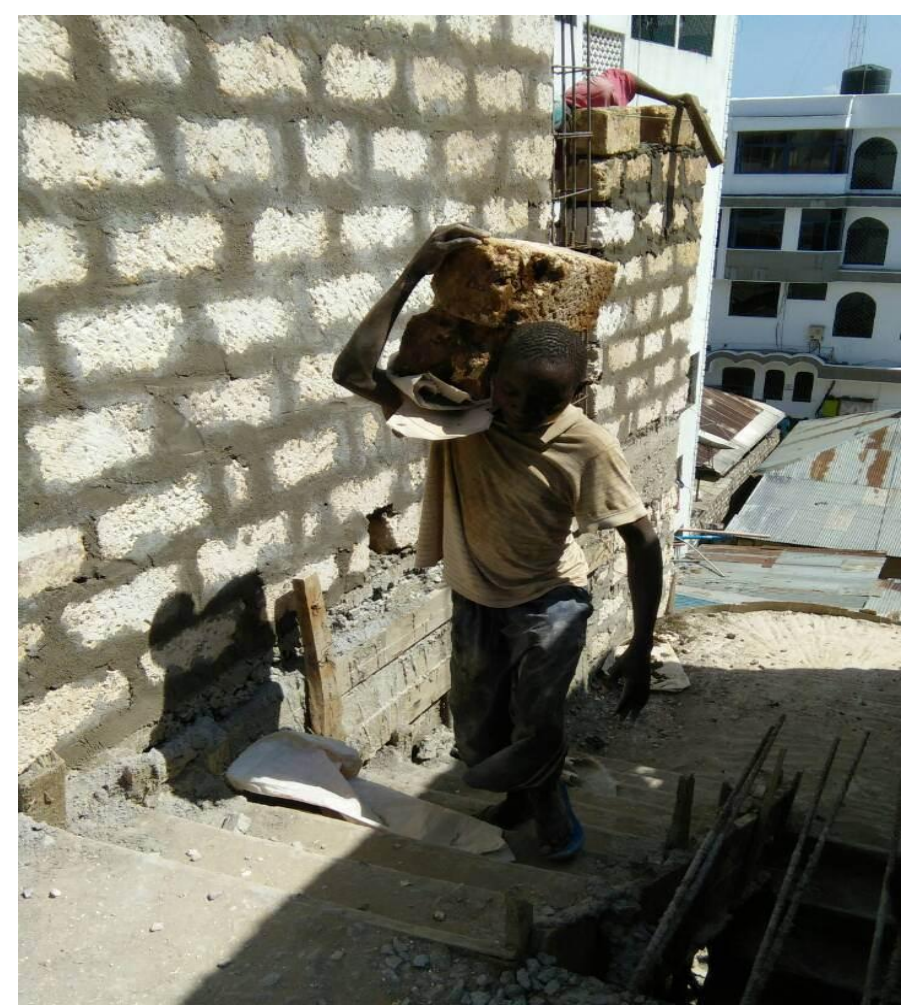

Plate 2:- A casual worker carrying building blocks (average weight 20kg) to fourth floor

Other worker activities involved working with arms above shoulder level for long hours and with the neck in fixed positions, conditions that promote development of MSDs (Plate 3 and 4) 


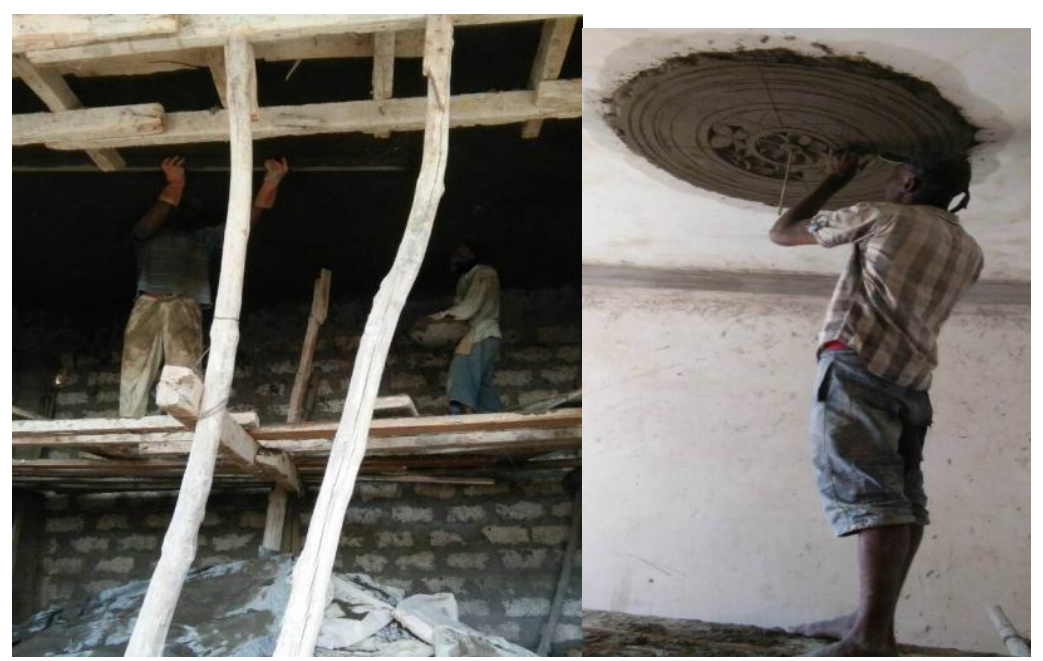

Plate 3:- Mason with arms above shoulder level; Plate 4: Ceiling decorator with neck in fixed position

\section{Prevalence of MSD symptoms;-}

The current finding has established that most (98.1\%) of the housing construction workers in Mombasa County experienced body pain, an MSD symptom as a result of their daily work activities. The pain was experienced in multiple body parts with $12 \%$ of the respondents reporting pain of the neck, shoulders and hands while $86.1 \%$ reported pain of upper and lower limb, knees, ankles and feet. This study finding agree with Oude et al., (2011) who established that in any population of working construction workers, more than half suffer from occasional or frequent musculoskeletal complaints. Also, the European Foundation for the Improvement of Living and working Conditions (1997) asserts that $47 \%$ of lost work days result from MSDs such as low back pain and carpal tunnel syndrome in the European Union and the highest number is in the construction industry.

The respondents also experienced body pain for varying duration. Majority 59.5\% experienced body pain consistently for 3-5days, $26.8 \%$ for 6-8 days while $11 \%$ experienced body pain for over 8 days. This study finding affirms that housing construction workers in Mombasa County do indeed suffer from MSDs and agrees with Holmstrom et al., (1995) who asserts that $72 \%$ of all sick leaves greater than four weeks in the construction industry was related to MSDs in Swedish insurance companies.

The respondents cited that the MSDs they experienced were caused by physical factors (work activities), work procedures and exposure history (Figure 1).

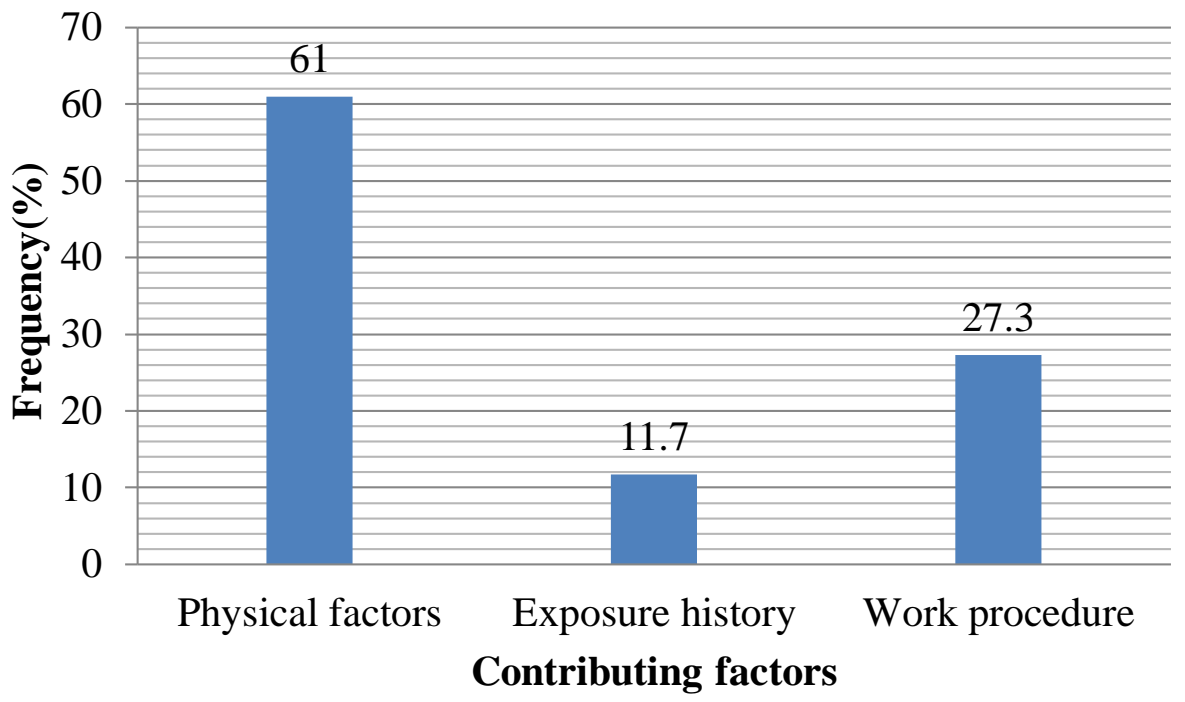

Figure 2:- Factors contributing to development of MSDs 


\section{Relationship of MSDs to occupational Activities:-}

From the findings of this study, there is a strong relationship between prevalence of MSD symptoms and work activities and the perception of MSD symptoms to be work-related by the workers. This was revealed by conducting multiple regression analysis using the equation: $\left.Y=\beta 0+\beta_{1} X_{1}+\varepsilon\right)$ to test and determine the prevalence of musculoskeletal disorders among housing construction workers in relation to occupational activities, presence of MSDs symptoms and perception of MSDs symptoms to be work-related. The regression model was found suitable for determining the regression equation. The $\mathrm{R}$ value for predicting occupational activities, presence of MSD symptoms and perception of MSDs relatedness to work was $0.867 \pm 0.313$. The R-Square value was 0.751 and Adjusted R-Square value was 0.750. Analysis of Variance (ANOVA) to test the fitness of regression model was found statistically significant at $\mathrm{p}=0.000(\mathrm{p} \leq 0.05)$ and the data obtained is significant (Table 5). With a constant (beta) of $0.689, \beta_{1}$ (performance/increase) of 0.716 with a significance level of 0.05 , the regression equation $\mathrm{Y}=\beta 0+$ $\left.\beta_{1} X_{1}+\varepsilon\right)$ become

$\mathrm{Y}=0.689+0.716 \mathrm{X}_{1}+0.05$

Where;

Y=Prevalence of MSDs

$\beta 0=$ constant

$\beta_{1=}$ (performance/increase)

$\mathrm{X}_{1}=$ independent variables (activities performed, presence of MSDs, perception of MSDs)

$\varepsilon=$ error of estimate at $95 \%$ confidence level.

Table 5:- Regression statistics ${ }^{\mathrm{a}}$

\begin{tabular}{|c|c|c|c|c|c|}
\hline \multirow[t]{2}{*}{ Model } & \multicolumn{2}{|c|}{$\begin{array}{l}\text { Unstandardized } \\
\text { Coefficients }\end{array}$} & $\begin{array}{l}\text { Standardized } \\
\text { Coefficients }\end{array}$ & \multirow[t]{2}{*}{ t-value } & \multirow[t]{2}{*}{ Sig. } \\
\hline & $\mathrm{B}$ & Std. Error & Beta & & \\
\hline (Constant) & 0.689 & 0.101 & & 6.828 & 0.000 \\
\hline $\begin{array}{l}\text { Occupational activities, presence } \\
\text { of MSDs and perception of } \\
\text { MSDs to be work-related }\end{array}$ & 0.716 & 0.025 & 0.867 & 28.130 & 0.000 \\
\hline
\end{tabular}

Chi Square value:-

The chi square was also calculated to test the significant of association between the variables (Table 6). The obtained chi value $=0.657, p=.000$. This value shows that there is statistically significant association between the variables.

Improvement of work Environment in construction sites:-

It was established in this study that only $2.7 \%$ of the respondents reported workplace injuries to a medical practitioner while the majority (96.9\%) either did not report at all or they reported to workmates, foreman or contractor and no further action was taken. Those who did not report at all to anyone argued that they feared being victimized or denied contracts and the casual construction jobs are their only way of obtaining livelihood. The low rate of reporting can be attributed to ignorance of the law on employees' right to a safe workplace. The Kenya OSHA 2007 directs all employers to register their work places with DOSHS and have a general register on site where all occurrences are recorded daily. When the respondents were asked about their opinion on what could be done to make their workplace more comfortable and safe, majority $99.1 \%$ (262) recommended improvement of their work environment through job rotation, manageable workloads, better wages and provision of PPE.

\section{Conclusion:-}

This study concludes that housing construction workers in Mombasa County do indeed experience MSDs symptoms as a result of their work. Physical factors such as handling heavy weights, working in awkward postures and doing repetitive jobs lead to development of MSDs. Additionally, poor work procedures such as working for long hours, using un-serviced or improvised tools, allocation of large workloads and lack of job rotation lead to development of MSD symptoms. Exposure history also contributes to development of MSD symptoms among housing construction workers. This study also concludes that very little has been done to control MSDs among workers in the housing 
construction industry. Enforcement of OSHA, 2007 is yet to be fully applied in the housing construction industry in Mombasa County.

\section{Recommendations:-}

This study recommends application of job rotation and breaks in between working hours to ensure that strenuous activities are not performed for long hours, regular servicing of tools and equipment to reduce health risks to housing construction workers in Mombasa County. The study further recommends enforcement of both OSHA, 2007 and NCA 2011 through provision of PPE and strict supervision of the housing construction industry as well as awareness creation on safe work practices to minimize prevalence of MSDs.

\section{Acknowledgement:-}

The authors would like to appreciate the academic staff of IEET, Jomo Kenyatta University of Agriculture and Technology for their resourcefulness. Special thanks to the course coordinator JKUAT-Mombasa Campus, Ms. Mary Kerich for her selfless guidance.

\section{References:-}

1. Babbie, E., (2004), The Practice of Social Research. Belmont CA, Wadsworth.

2. Bernard, B. P. (2010). Musculoskeletal disorders and workplace factors: a critical review of epidemiologic evidence for work-related musculoskeletal disorders of the neck, upper extremity, and lower back. NIOSH Publication No. 97141.

3. DHHS (2004). Musculoskeletal disorders and work-place factors- a critical review of epidemiologic evidence for work-related musculoskeletal disorders of the neck, upper extremity and low back. NIOSH publication.

4. DHHS (1997). Musculoskeletal disorders and work-place factors- a critical review of epidemiologic evidence for work-related musculoskeletal disorders of the neck, upper extremity and low back. NIOSH publication.

5. European Foundation for the Improvement of Living and Working Conditions (1997).

6. Preventing Absenteeism at the workplace. Research summary. Office for official publication of the European Communities.

7. Flanagan, F. Jewell, C. Larsson, B. and Sfeir, C. (2001). "Vision 2020: Building Sweden's future”, Department of Building Economics and Management, Chalmers University of Technology, Sweden. 111 p.

Government of Kenya (2007). Kenya gazette supplement number 111 (Acts No. 15). The Occupational Safety and Health Act (OSHA), Government printer, Nairobi.

8. Government of Kenya (2007). Kenya gazette supplement. The Work Injury Benefits Act (WIBA), Government printer, Nairobi

9. Government of Kenya (2007). Kenya gazette supplement. The Labour Institution Act Government printer, Nairobi

10. Hair, Jr. J. F., Anderson, R. E., Tatham, R. L. and Black, W. C., (1998), Multivariate Data Analysis (5th Ed.). New York: Macmillan Publishing Company.

11. Holmstrom, E. and Engholm, G. (2003). Musculoskeletal disorders in relation to age and occupation in Swedish construction workers. American Journal of Industrial Medicine. 44:377-384.

12. Hoogendoorn WE, Poppel MNM Van and Bongers PM (1999). Physical load during work and leisure time as risk factors for back pain Scand J Work Environ Health 25:387-40

13. Latza, U. Karmaus, W. Sturmer, T. Steiner, M. Neth, A and Rehder, U. (2000) Cohort study of occupational risk factors of low back pain in construction workers. Journal of Occupational Environmental Medicine. 57:28-34.

14. Levin, K. A. (2006). Study design III: Cross-sectional studies. Evidence-based Dentistry, 7(1)

15. Mugenda, O.M. and Mugenda, A.G., (1999), Research Methods: Quantitative and Qualitative approaches. Nairobi, Kenya: Act Press.

16. Oude, K.M. Blatter, B. Geuskens, G.A. and Koppes, L.L. (2011). Factors associated with the ability and willingness to continue working until the age of 65 in construction workers. International Journal of Occupational and Environmental Health.

17. Schneider S. P. (2001). Musculoskeletal Injuries in Construction: A review of the Literature. Journal of Applied Occupational Environmental Hygine 16(11): 1056-1064.

18. Stattin, M. and Järvholm, B. (2005). Occupation, work environment, and disability pension: a prospective study of construction workers. Scandinavian Journal of Public Health 2005;33: 84-90.

19. Swedish Government (2004). Swedish Social Insurance Agency. Sweden.

20. U.S Department of Health and Human Services (1997). Work practices guide for manual lifting. DHHS (NIOSH), Publication No. 81-122.

21. U.S National Research Council and the Institute of Medicine (2001). Musculoskeletal disorders and the workplace: low back and upper extremities. National Academy Press. 